\title{
EL EFECTO DEL TIPO DE CAMBIO EN LA CONTABILIDAD DE LAS EMPRESAS
}

\author{
ROSELLA URDANEGUI \\ - Profesora de Introducción a la Contabilidad \\ Carrera de Contabilidad y Administración \\ Facultad de Negocios, UPC
}

Una de las variables más importantes al medir el riesgo al que están expuestas las empresas es su posición en moneda extranjera; es decir, aquella situación que permite conocer cuáles son los pasivos y activos en dólares y a cuánto ascienden. A la diferencia entre ambos, se le conoce como exposición neta.

En nuestro país, en los años 2009 y 2012 hubo una caída del precio del dólar, conocida como apreciación del sol. Esto dio como resultado una mayor utilidad en sus estados financieros para aquellas empresas que estaban desprotegidas frente al riesgo de las fluctuaciones de cambio.

\section{UNA DE LAS VARIABLES MÁS IMPORTANTES AL MEDIR EL RIESGO AL QUE ESTÁN EXPUESTAS LAS EMPRESAS ES SU POSICIÓN EN MONEDA EXTRAN.JERA...}

Este mismo escenario ocurrió nuevamente en los meses de marzo y abril del presente año. Sin embargo, las empresas que mantenían cuentas por cobrar en dólares, experimentaron una disminución en su utilidad.

Como se observa en la figura 1, desde el año 2013 la depreciación del sol ha sido continua, alcanzando niveles tales que para el año 2013 fue de $9.60 \%$; en 2014, de 6.90\% y en el 2015, de 14.19\%. Al cierre del año 2015, para efectos tributarios, el tipo de cambio de cierre para los activos fue de S/.3.408 (compra) y para los pasivos S/.3.413 (venta). Como consecuencia de ello, muchas empresas peruanas se han visto afectadas debido a estas fluctuaciones al contar con mayores pasivos que activos en dólares.

\section{Figura 1: Tipos de cambio al cierre anual}

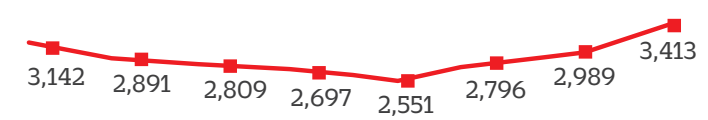

$\begin{array}{llllllll}2008 & 2009 & 2010 & 2011 & 2012 & 2013 & 2014 & 2015\end{array}$

Fuente: Adaptado de SBS (2015)
Debido a la volatilidad del tipo de cambio, se originan diferencias cambiarias que modifican los estados financieros, en algunos casos de manera drástica, dando como resultado la reducción de las utilidades, llegando incluso a tener pérdidas como consecuencia del ajuste cambiario. Solo bajo la premisa de una depreciación del sol, es decir, un aumento en el tipo de cambio, las empresas (en el supuesto caso de contar con mayores pasivos que activos en dólares), obtendrán pérdida por diferencia de cambio en sus estados financieros. Este riesgo cambiario genera incertidumbre en la gerencia para la toma de decisiones.

Ante la fluctuación del dólar, podemos indicar que las empresas más vulnerables ante una subida del dólar son las importadoras de insumos o productos como las empresas industriales y de consumo masivo, esto siempre y cuando la facturación se realice en soles. Por otro lado, las empresas que están cubiertas a la depreciación del sol son aquellas que han logrado vender y comprar en la misma moneda, tal es el caso de las mineras, las agroexportadoras y las pesqueras.

\section{DEBIDO A LA VOLATILIDAD DEL TIPO DE CAMBIO, SE ORIGINAN DIFERENCIAS CAMBIARIAS QUE MODIFICAN LOS ESTADOS FINANCIEROS, EN ALGUNOS CASOS DE MANERA DRÁSTICA, DANDO COMO RESULTADO LA REDUCCIÓN DE LAS UTILIDADES, LLEGANDO INCLUSO A TENER PÉRDIDAS COMO CONSECUENCIA DEL AJUSTE CAMBIARIO}

Cabe resaltar que no existe ninguna estimación certera del precio relativo futuro del dólar. Desde inicios del año, diversas entidades nos han mostrado diferentes estimaciones realizadas. Asimismo, en los últimos días se ha dado a conocer la estimación del dólar y es menor a la que se brindó a inicios de año, esto se debe a que hay factores externos que inciden en ese valor, tales como la decisión de la FED, en Estados Unidos de subir la tasa de interés de referencia; la salida de Inglaterra de la 
Unión Europea; el retiro de fondos de AFP por parte de los jubilados; entre otros. Lo cierto es que seguiremos teniendo incertidumbre sobre ello.

Pero ¿qué medidas pueden adoptar las empresas para no verse afectadas ante una posible depreciación del sol? En primer lugar, deben conocer su posición en relación al grado de exposición a la fluctuación del dólar y vigilar constantemente esa situación. Solo con ello se podrán tomar acciones en relación al endeudamiento. En ese sentido, siempre debe existir una correlación entre ingresos y pagos, considerando que es conveniente que ambos se encuentren en la misma moneda. Una alternativa que tienen las empresas a esta situación es cambiar las deudas de dólares a soles, en caso no puedan facturar en dólares. En segundo lugar, pueden cubrirse con las diferentes opciones de cobertura de riesgo cambiario entre las que figuran los forwards, derivados, swaps, entre otros; de tal manera que la empresa asegura y fija por adelantado el tipo de cambio, cubriendo con esta medida las fluctuaciones futuras del mismo.

Dentro de este contexto, no tenemos certeza del tipo de cambio de cierre del presente año, pero las empresas deben estar preparadas para las futuras fluctuaciones. Es importante conocer que los resultados obtenidos por las empresas al cierre del 2015, según la información presentada a la Superintendencia del Mercado de Valores, muestra que algunas de ellas no fueron capaces de controlar el efecto negativo que hubo como consecuencia del incremento del tipo de cambio, generando en muchos casos una pérdida por diferencia de cambio en su información financiera.

\section{REFERENCIAS}

SBS. (2015). Obtenido de Superintendencia de Banca, Seguros y AFP: http://www.sbs.gob.pe/app/stats/tc-cv.asp 